\title{
Selection and validation of endogenous reference genes using a high throughput approach
} Ping Jin ${ }^{\dagger 1}$, Yingdong Zhao ${ }^{\dagger 2}$, Yvonne Ngalame ${ }^{1}$, Monica C Panelli ${ }^{1}$, Dirk Nagorsen ${ }^{1}$, Vladia Monsurró ${ }^{1}$, Kina Smith ${ }^{1}$, Nan $\mathrm{Hu}^{2}$, Hua Su${ }^{2}$, Phil R Taylor ${ }^{2}$, Francesco M Marincola*1 and Ena Wang ${ }^{1}$

\author{
Address: ${ }^{1}$ Immunogenetics Section, Department of Transfusion Medicine, Clinical Center, NIH Bethesda, MD 20892, USA and ${ }^{2}$ Biometric \\ Research Branch, Division of Cancer Treatment and Diagnosis, Cancer Prevention Studies Branch (CPSB), National Cancer Institute, National \\ Institutes of Health, Bethesda, MD 20892, USA \\ Email: Ping Jin - pjin@mail.cc.nih.gov; Yingdong Zhao - zhaoy@ctep.nci.nih.gov; Yvonne Ngalame - yngalame@mail.cc.nih.gov; \\ Monica C Panelli - mpanelli@mail.cc.nih.gov; Dirk Nagorsen - nagorsen@medizin.fu-berlin.de; \\ Vladia Monsurró - VMousurro@mail.cc.nih.gov; Kina Smith - ksmith2@mail.cc.nih.gov; Nan Hu - hun@dcpcepn.nci.nih.gov; \\ Hua Su - suhu@mail.nih.gov; Phil R Taylor - ptaylor@mail.nih.gov; Francesco M Marincola* - fmarincola@mail.cc.nih.gov; \\ Ena Wang - ewang@mail.cc.nih.gov \\ * Corresponding author †Equal contributors
}

Published: 13 August 2004

BMC Genomics 2004, 5:55 doi:10.1 186/147/-2164-5-55

This article is available from: http://www.biomedcentral.com/I47/-2/64/5/55

(c) 2004 Jin et al; licensee BioMed Central Ltd.

This is an open-access article distributed under the terms of the Creative Commons Attribution License (http://creativecommons.org/licenses/by/2.0), which permits unrestricted use, distribution, and reproduction in any medium, provided the original work is properly cited.
Received: 25 March 2004

Accepted: 13 August 2004

\begin{abstract}
Background: Endogenous reference genes are commonly used to normalize expression levels of other genes with the assumption that the expression of the former is constant in different tissues and in different physiopathological conditions. Whether this assumption is correct it is, however, still matter of debate. In this study, we searched for stably expressed genes in 384 cDNA array hybridization experiments encompassing different tissues and cell lines.
\end{abstract}

Results: Several genes were identified whose expression was highly stable across all samples studied. The usefulness of 8 genes among them was tested by normalizing the relative gene expression against test genes whose expression pattern was known. The range of accuracy of individual endogenous reference genes was wide whereas consistent information could be obtained when information pooled from different endogenous reference genes was used.

Conclusions: This study suggests that even when the most stably expressed genes in array experiments are used as endogenous reference, significant variation in test gene expression estimates may occur and the best normalization is achieved when data from several endogenous reference genes are pooled together to minimize minimal but significant variation among samples. We are presently optimizing strategies for the preparation of endogenous reference gene mixtures that could yield information comparable to that of data pooled from individual endogenous reference gene normalizations.

\section{Background}

Endogenous reference alse referred to as house keeping genes defines in biology the theoretical assumption that certain genes are ubiquitously expressed in nucleated cells possibly because their stable expression is essential for cell survival and welfare in all physio-pathological 
circumstances. In practical terms, endogenous reference genes provide a useful constant reference to normalize the expression of test genes in different tissues and in different conditions. This is obviously important when estimates of gene expression are provided in relative terms rather than absolute units of measurement. Thus, endogenous reference genes are used as common denominator in biological fractions where the expression of a test gene is described as the relative ratio over an arbitrarily selected internal control presumed to be stably expressed in all circumstances relevant to the experiment [1-3]. Most frequently, glyceraldehydes-3-phosphate dehydrogenase (GAPDH) [4,5], albumin (for hepatocytes) [6], $\beta$-, $\gamma$-actins $[7,8]$, cyclophilin $[9,10], \alpha-, \beta$-tubulins $[7,11]$, hypoxantine phosphoribosyltransferase (HRPT) [12,13], L32 $[14,15]$ and 18S, 28S ribosomal RNA (rRNA) [16-18] have been used as endogenous reference genes. Depending upon the experimental design, endogenous reference genes have been used individually or in combination for Northern blot analysis, reverse transcription polymerase chain reaction (RT-PCR) and quantitative real-time PCR (qRT-PCR) analysis $[19,20]$. With the development cDNA microarray technology endogenous reference genes have been used for array data normalization. However, accumulation of extensive data bases suggests that the expression of frequently used endogenous reference genes can vary substantially according to materials and conditions studied $[1,2,6,14,17,18,20-27]$.

Powerful insights in patterns of gene expression could be attained recently through cDNA or oligonucleotide-based global transcript analysis tools that apply a constant reference system to determine ratios of gene expression across large data sets $[28,29]$. The constant reference is provided for each gene in question by consistently co-hybridizing individual test samples with a differentially labeled reference sample maintained identical throughout all the hybridization experiments. Gene expression data are then expressed as the ratio of expression between test and reference samples for each gene. By keeping the reference sample identical the resulting ratio represents a precise estimate of the relative expression of each gene across the various conditions tested bypassing the need to normalize with endogenous reference genes. This holds true if the hybridization kinetics between test and reference sample are accurately reproducible. We will refer to this concept as "reference concordance" and in the results we will discuss how reference concordance was used to validate the reproducibility of cDNA array data from which putative candidate endogenous reference genes were identified.

In the present study, we tested a set of 419 consecutive experiments performed on a 17,000 gene cDNA array platform to which RNA from neoplastic or normal tissues were consistently co-hybridized with a differentially- labeled reference RNA derived from peripheral blood mononuclear cells (PBMC) pooled from six normal donors. The following steps were pursued: 1) Reproducibility assessment of the data set through determination of reference concordance. This was achieved by repeating 14 reference experiments using the melanoma cell line A375 as test sample (Cy5) co-hybridized with pooled PBMC as reference (Cy3). To test for inter-array and printing variation, slide number one and every other 25 slides in sequential order of printing (100 slides per printing set) were used for the repetitive A375 / pooled PBMC hybridizations. In addition, to assess labeling bias, reciprocal labeling was alternatively applied as previously described [30]. In this fashion a pool of genes expressed with high level of reference concordance was selected. 2) Identification of putative endogenous reference genes was performed on 384 array experiments of unequivocal quality by selecting genes that had demonstrated high reference concordance ( $>90 \%$ of the genes in the arrays) and ranking them from the lowest to the highest variance of ${ }_{\log 2}$ test / reference ratios across all array experiments. 3) Validation of the candidate endogenous reference genes as predictor of relative gene expression in large data series. For this purpose, we tested the relative estimates of expression of the melanocytic lineage-restricted melanoma differentiation antigen gp100/Pmel17 (gp100) [31] in melanocytic and non-melanocytic tissues. Estimates of expression of gp100 were compared after normalization with different endogenous reference genes. For this analysis, we used a new tool that spots cDNA libraries from different tissues on an array platform to allow highthroughput evaluation of individual gene expression across broad tissue collections. We termed this tool: "transcriptome array". 4) Validation of endogenous reference gene-based normalization of gene expression by qRT-PCR and protein expression.

\section{Results \\ Data processing}

The GenePix Pro 4.0 software was used for array image analysis and calibration. All statistical analyses were performed with the SPLUS package http://www.insight ful.com. Thirteen arrays with missing data in more than $30 \%$ of the spots and 8 arrays with irregular distribution according to $\mathrm{M}$-A plots ( $\mathrm{M}$ and A representing respectively log-ratios and average intensities) [32] were excluded. Spots in which $>50 \%$ of the pixels reached saturation in either channel, flagged spots and spots with intensity $\leq$ 200 in one channel and $\leq 500$ in the other channel were filtered out. If the intensity in one channel was $<200$ but that of the other channel was > 500, we arbitrarily assigned an intensity of 200 to the channel with the lowest intensity. The $\log _{2} \mathrm{Cy} 5 / \mathrm{Cy} 3$ ratios were normalized by approximating median values to zero. Spots with ratios > 100 or $<1 / 100$ were truncated at 100 and $1 / 100$ 
respectively. Data normalization was done by median centering $\log 2_{2}$ ratio of all genes for each array. For data normalization we used certain arbitrary cutoff criteria to remove spots with weak signal. Weak signal approximating background fluorescence is not reliable and the corresponding log ratios are often distorted resulting in disproportionately high or low values that would bias the statistical results. Because the interpretation of spots with low signal is difficult to make we have adopted the policy of excluding them to focus the analysis on genes whose expression pattern is more reliably tracked by the array tool. In regard to spots with a ratio of $>100$ or $<-1 / 100$, most of them are due to extremely weak signal in one channel which generates a disproportionately extreme value. Although there is no published "gold standard" for the selection of such cutoffs, in practice the parameters that we used for this study are most commonly accepted by investigators and reasonable because allow retention of most of the data in the array excluding only the most extreme and least reliable information.

\section{Validation of the data set through analysis of "reference concordance"}

To select from the data base the most reliable genes, we first assessed reproducibility by testing the level of concordance in 14 reference experiments. Reference concordance relies on the expectation that results obtained by repeatedly hybridizing the same test and reference material should perfectly collimate and the degree of deviation from such prediction estimates experimental variance. Concordance can be easily measured by periodically rehybridizing the same test sample with the constant reference sample. We analyzed a matrix of 7 forward and 7 reciprocally-labeled replicate array experiments hybridized periodically every other 25 cDNA array slides. Reciprocal labeling was applied to measure labeling bias [30]. Data generated by reciprocal experiments were mathematically reversed into the same labeling direction for data analysis. Genes that were discordant due to labeling bias were identified by student's $t$ test as those with ratios significantly different between the 7 forward and 7 reciprocal experiments after reversal of the reciprocal values $(\mathrm{P}<$ 0.05 ) and the median ratio difference between the 7 forward and 7 reciprocal experiments was larger than 1.5 fold. The genes whose variances of the log ratio across all experiments were among the top 1 percentile of variance of all genes were identified as discordant due to hybridization bias. In addition, genes with more than 50\% missing values were excluded. Overall 1,343 out of 16,738 were judged potentially discordant and were excluded from further analysis. The remaining 15,395 concordant genes were used for subsequent analyses.

\section{Endogenous reference gene identification}

We studied 384 of 419 consecutive array experiments remaining after the exclusion of the 14 reference concordance experiments and 21 experiments judged of poor quality due to missing data or irregular distribution by $\mathrm{M}$ A plot analysis. Selection of candidate endogenous reference genes followed these steps.

First, the seven experiments used for the analysis of reference concordance in which labeling was done identically to the rest of the experimental samples (test labeled with Cy5 and reference with Cy3) were used to calculate experimental variance (Table 1). Median of variances across the seven replicate arrays was calculated for all genes with average intensity in both channels $>2,000$. This parameter provides an estimate of the variance due to experimental variation (background variance) since theoretically no differences in gene expression should be noted by using the same material. Based on the assessment of the seven repeat experiments, we defined differential expression as $>2$ standard deviations (SD) from the mean of the 384 arrays which is equivalent to 1.46 -fold change $( \pm 0.549$ in $\log 2$ ratio). Consequently, genes with fold changes $<1.46$ from zero across all 384 arrays were categorized as candidate endogenous reference genes and were ranked according to ascending values of SD of ${ }_{\text {Log }}$ ratio (Table 1 ).

Among these genes, we further selected candidate endogenous reference genes according to the following criteria: in at least $95 \%$ of the 384 arrays the $\log _{2}$ ratio had to be within 2 SD from zero and the average intensities of both channels across all samples need to be higher than 2,000. The intensity parameter was added to ensure that the selected endogenous reference genes were expressed at a relatively high level in most tissues to mitigate excessive fluctuations in $\log _{2}$ ratios occurring when a low value is applied as denominator. This is important when a reference gene is applied as a denominator in the equation used to normalize the ratio of other tests genes; in such cases robust gene expression decreases the range of ratios resulting from the analysis decreasing, therefore, the experimental variance. Sixty-nine genes fit these criteria. The range of mean $\log 2_{2}$ ratio was from 0 to 0.15 and the SD of mean $\log 2_{2}$ ratio was from 0.27 to 0.42 . Analysis of 7 replicate array based on the same group of candidate endogenous reference genes demonstrated a similar distribution of mean $\log _{2}$ ratio and $S D$ of mean $\log _{2}$ ratios (with exception of TFAP2B) suggesting that this variance could be attributed to predominantly experimental noise. Among these genes we further selected for validation 11 that had high mean fluorescence intensity (underlined in Table 1). However, probe preparation and other technical considerations limited to analysis to only 8 of these genes which included: NEED8, HIRIP5, GPLD1, RAB31, SNRPD3, FZD6, COL8A1 and AFAP. 
Table I

\begin{tabular}{|c|c|c|c|c|c|c|c|}
\hline \multirow[b]{2}{*}{ Gene Name } & \multirow[b]{2}{*}{ Image ID } & \multirow[b]{2}{*}{ Unique ID } & \multirow[b]{2}{*}{$\begin{array}{c}\text { Mean } \\
\text { Intensity }\end{array}$} & \multicolumn{2}{|c|}{384 experiments } & \multicolumn{2}{|c|}{7 replicates } \\
\hline & & & & $\begin{array}{l}\text { Mean of } \\
\text { logRatio }\end{array}$ & $\begin{array}{c}\text { SD of } \\
\text { logRatio }\end{array}$ & $\begin{array}{l}\text { Mean of } \\
\text { logRatio }\end{array}$ & $\begin{array}{c}\text { SD of } \\
\text { logRatio }\end{array}$ \\
\hline cDNA FLJ40458 & $157 \mid 492$ & Hs. 181346 & 2835 & 0.19 & 0.27 & 0.39 & 0.15 \\
\hline Unknown & 301067 & & 2571 & 0.1 & 0.27 & 0 & 0.21 \\
\hline PTH & $\underline{322051}$ & Hs.37045 & 3380 & $\underline{0}$ & $\underline{0.28}$ & -0.02 & 0.27 \\
\hline KIAAI935 & 39938 & Hs.300776 & 2359 & 0.16 & $\overline{0.28}$ & $\overline{0.01}$ & 0.19 \\
\hline ESTs & 49313 & Hs.395460 & 2079 & 0.15 & 0.28 & 0.08 & 0.03 \\
\hline cDNA FLJ30539 fis & 49463 & Hs.21489 & 2561 & 0.09 & 0.28 & 0.17 & 0.13 \\
\hline SDCCAGI6 & 1576228 & Hs.27I926 & 2111 & 0.11 & 0.29 & 0.28 & 0.14 \\
\hline clone IMAGE:4I 799 & 278673 & Hs.27|72I & 3132 & 0.16 & 0.3 & -0.04 & 0.1 \\
\hline PSIP2 & 289945 & Hs.82II0 & 2521 & -0.07 & 0.3 & -0.06 & 0.19 \\
\hline ETV2 & 1468722 & Hs.19406I & 2646 & 0.09 & 0.31 & 0 & 0.28 \\
\hline ESTs & $157|40|$ & Hs. 126999 & 2659 & 0.05 & 0.31 & -0.04 & 0.08 \\
\hline NEDD8 & 277660 & Hs. 75512 & $\underline{3875}$ & 0.08 & $\underline{0.31}$ & $\underline{0.1}$ & 0.2 \\
\hline HIP2 & $\overline{486259}$ & $\overline{H s .155485}$ & $\overline{2511}$ & $\overline{0.11}$ & $\overline{0.31}$ & $\overline{0.12}$ & $\overline{0.25}$ \\
\hline HIRIP5 & 745314 & Hs.430439 & 3407 & -0.08 & 0.31 & 0.07 & 0.31 \\
\hline ACTR8 & 156363 & Hs. 124219 & 2731 & 0.08 & 0.32 & 0.14 & 0.16 \\
\hline GPLDI & 293696 & Hs. 272529 & 3110 & -0.03 & 0.32 & -0.05 & 0.28 \\
\hline KIAA0769 & 299128 & Hs. 19056 & 2148 & 0.14 & 0.32 & 0.05 & 0.2 \\
\hline CSNKIG2 & 346031 & Hs. 181390 & 2320 & -0.03 & 0.32 & -0.24 & 0.28 \\
\hline RAB31 & 784150 & Hs. 223025 & 3479 & -0.06 & 0.32 & -0.36 & 0.36 \\
\hline Cl4orflI7 & 796100 & Hs. 103189 & 2008 & 0.12 & 0.32 & $\overline{-0.01}$ & 0.16 \\
\hline ATP6IP2 & 825077 & Hs. 183434 & 2159 & 0.02 & 0.32 & 0.28 & 0.32 \\
\hline SNRPD3 & 897099 & Hs. 1575 & 3031 & -0.04 & 0.32 & -0.48 & 0.25 \\
\hline$\overline{\text { Unknown }}$ & $\overline{1292073}$ & & $\overline{2745}$ & $\overline{-0.13}$ & $\overline{0.33}$ & $\overline{0.05}$ & $\overline{0.28}$ \\
\hline ESTs & 22137 & Hs. 187406 & 3133 & 0.07 & 0.33 & -0.01 & 0.21 \\
\hline ESTs & 32782 & Hs. 443 I 40 & 2464 & -0.02 & 0.33 & 0.09 & 0.26 \\
\hline L3MBTL & 43090 & Hs.300863 & 2581 & -0.08 & 0.33 & $-0.4 I$ & 0.31 \\
\hline GNRHI & 48707I & Hs.82963 & 3294 & 0.05 & 0.33 & 0.23 & 0.23 \\
\hline clone 24629 mRNA & 746258 & Hs. 142570 & 2645 & 0.05 & 0.33 & -0.21 & 0.14 \\
\hline FLJ 12998 & 826367 & Hs. 343627 & 2267 & 0.14 & 0.33 & 0.03 & 0.3 \\
\hline cDNA: FLJ23477 fis & 1492329 & Hs. 145362 & 2142 & 0.09 & 0.34 & 0.35 & 0.34 \\
\hline HOXC4 & 1756945 & Hs.50895 & 2581 & 0.03 & 0.34 & -0.02 & 0.22 \\
\hline WSXI & 1855887 & Hs. I3278I & 3259 & -0.01 & 0.34 & 0.12 & 0.3 \\
\hline HISTIHIA & 1872543 & Hs. 150206 & 2523 & 0.07 & 0.34 & -0.17 & 0.14 \\
\hline TFAP2B & 363144 & Hs.33102 & 2510 & 0.05 & 0.34 & 0.67 & 0.35 \\
\hline TRIM3I & 509760 & Hs.91096 & 2753 & 0.06 & 0.34 & -0.08 & 0.2 \\
\hline FLJ00166 & 713191 & Hs. 43213 & 3134 & 0.08 & 0.34 & 0 & 0.22 \\
\hline CDK5RI & 757873 & Hs. 93597 & 2965 & -0.12 & 0.34 & -0.22 & 0.15 \\
\hline$\overline{\text { PPP3CA }}$ & $\overline{796730}$ & $\overline{H s .272458}$ & $\overline{2605}$ & $\overline{-0.07}$ & $\overline{0.34}$ & $\overline{-0.36}$ & $\overline{0.16}$ \\
\hline PMS2L4 & 161373 & Hs. 278468 & 2534 & -0.14 & 0.35 & -0.21 & 0.22 \\
\hline DLGAPI & $|75849|$ & Hs.758I4 & 2143 & 0.02 & 0.35 & -0.24 & 0.2 \\
\hline ESTs & 177884 & Hs. 14613 & 2054 & 0.01 & 0.35 & -0.22 & 0.25 \\
\hline NRL & 2364249 & Hs.89606 & 2300 & -0.04 & 0.35 & -0.09 & 0.14 \\
\hline RAB36 & 281489 & Hs.38772 & 3143 & -0.08 & 0.35 & 0 & 0.12 \\
\hline RPC8 & 323603 & Hs.353/92 & 2367 & -0.06 & 0.35 & -0.33 & 0.24 \\
\hline ZNFI77 & 33294 & Hs. 172979 & 2988 & 0.01 & 0.35 & -0.21 & 0.25 \\
\hline LY6G5C & 448136 & Hs. 246845 & 3591 & -0.02 & 0.35 & -0.44 & 0.28 \\
\hline RADI7 & 586844 & Hs. 16184 & 3797 & -0.01 & 0.35 & 0.12 & 0.15 \\
\hline LOC253039 & 1033388 & Hs.4II8I & 3612 & -0.02 & 0.36 & 0.31 & 0.08 \\
\hline IMPDH2 & 1582050 & Hs.75432 & 2709 & -0.01 & 0.36 & -0.08 & 0.18 \\
\hline PRMT3 & 2074202 & Hs. 152337 & 2042 & 0.07 & 0.36 & -0.06 & 0.21 \\
\hline FZD6 & 214916 & Hs. 114218 & 3884 & $\underline{0.03}$ & $\underline{0.36}$ & 0.02 & $\underline{0.26}$ \\
\hline AP3B2 & 47510 & Hs.21022 & 2350 & 0.03 & 0.36 & -0.23 & 0.31 \\
\hline NF2 & 769716 & Hs. 902 & 2887 & -0.08 & 0.36 & -0.11 & 0.31 \\
\hline SCP2 & 855395 & Hs.75760 & 3218 & -0.12 & 0.36 & -0.1 & 0.19 \\
\hline COL8AI & 1472775 & Hs. 114599 & 4178 & -0.06 & 0.37 & 0.05 & 0.18 \\
\hline AKAP4 & 1643144 & Hs.97633 & 2557 & -0.03 & 0.37 & -0.07 & 0.15 \\
\hline
\end{tabular}


Table I (Continued)

\begin{tabular}{|c|c|c|c|c|c|c|c|}
\hline Unknown & 1671546 & & 3386 & 0.03 & 0.37 & $T$ & 0.42 \\
\hline TCF8 & 178463 & Hs.232068 & 2726 & -0.04 & 0.37 & -0.01 & 0.06 \\
\hline TNP2 & 1839038 & Hs. 2748 & 2737 & 0.08 & 0.37 & 0.11 & 0.24 \\
\hline PIWILI & 2329739 & Hs. 194712 & 2573 & -0.08 & 0.37 & -0.14 & 0.22 \\
\hline DBCCRI & 47037 & Hs.6090 & 2481 & -0.01 & 0.37 & -0.18 & 0.24 \\
\hline SLC2IA3 & 289706 & Hs.46440 & 2708 & 0 & 0.38 & -0.11 & 0.27 \\
\hline ESTs & 35105 & Hs.403854 & 3126 & 0.03 & 0.38 & 0.23 & 0.18 \\
\hline cDNA FLJ34400 fis & 511835 & Hs.380035 & 3058 & 0 & 0.38 & 0.02 & 0.37 \\
\hline CNTNI & 51640 & Hs. 143434 & 2479 & -0.05 & 0.38 & -0.11 & 0.3 \\
\hline TFCP2 & 843067 & Hs. I 54970 & 3728 & -0.06 & 0.38 & 0.16 & 0.34 \\
\hline Cl7orf35 & 510032 & Hs. 15196 & 2778 & -0.02 & 0.39 & 0.09 & 0.28 \\
\hline AFAP & 488062 & Hs. 80306 & 3142 & $\underline{0}$ & $\underline{0.42}$ & $\underline{0.12}$ & $\underline{0.15}$ \\
\hline MTP & 731054 & Hs. 195799 & 2764 & -0.01 & 0.42 & -0.09 & 0.4 \\
\hline
\end{tabular}

"Leave-one-out cross-validations" were used to estimate the error $[33,34]$. In each validation experiment one array was left out. The remaining 383 arrays were used to identify endogenous reference genes using the same parameters used for the original analysis (test/reference ratios $<2$ SD in at least $95 \%$ of the experiments and average intensity $>2,000$ in both channels). The median $\log _{2}$ ratio of the endogenous reference gene in the left out array was then compared with the "real" normalization factor consisting of the median $\log 2_{2}$ ratio for all genes in that array supposed to approximate a balanced expression of test and reference genes for that array. This procedure was repeated for each array 384 times. Only in 3 arrays out of 384 (2.3\%) were found errors in endogenous reference gene selection (errors were considered median $\log _{2}$ ratio of endogenous reference genes in the left out array $>2$ standard deviations apart from the "real" normalization factor in the same array (which is zero for normalized arrays).

The expression of each candidate endogenous reference gene identified in this study was then compared with available information about the expression of the same genes in 12 normal human tissues reported by the Affymetrix HG-U95A-E probe sets http://nci array.nci.nih.gov/cards/index.html. We found a good correlation between the expression patterns observed by us and that reported by the Affymetrix GeenChip array (data not shown). In addition, a cluster of endogenous reference genes suggested by Applied Biosystems for standardization during qRT-PCR was analyzed by evaluating the SD of their Log2 ratios across the 384 arrays. As data indicated in Table 2, although some genes (bold) demonstrated mean $\mathrm{SD}_{\log 2}$ ratios comparable to that of the endogenous reference genes identified in this study, the corresponding percentage of the arrays in which $\log 2_{2}$ ratios were within 2 SD from zero ranged between 0.68-0.85 which is significantly lower than the frequency in which the same parameter fell for the 69 candidate house keeping genes identified here (>95\%). In addition, we looked at the variation in our arrays of genes classically used as endogenous reference genes including: ribosomal protein L32, HRPT, $\beta$-actin and tubulin- $\alpha 3$. In all cases the mean $\mathrm{SD}$ of ${ }_{\log 2}$ Ratio was relatively larger than for the endogenous reference genes identified in Table 1 with the following respective values: 0.88 for Ribosomal protein L32, 1.13 for HRPT, 1.32 for $\beta$-actin and 1.42 for laminin- $\alpha 3$. Interestingly, however, the mean intensities were relatively higher for all of these genes compared with the ones identified in this study $(7,369 ; 12,778,43,794$ and 42,241 for the four genes respectively) suggesting that these genes are expressed probably at higher concentrations in tissue and, therefore, although relatively variable in expression in different tissues, they have been a useful marker of RNA abundance when only rough estimates are required like, for instance, for Northern Blotting.

\section{Test gene expression estimates according to house- keeping gene selection: the transcriptome array}

To validate the usefulness of candidate endogenous reference genes in large sample populations we developed a new tool that we are planning to use in the future for validation of gene expression across extensive data sets. This tool displays cDNA libraries originated from different tissues or cell lines individually spotted on a solid surface. The principle of this technology is similar to RNA dot blot which uses RNA isolated from samples and transferred to membrane making, therefore, the transcriptome array a high-density dot blot. The labeled DNA probe of interest is hybridized to the immobilized complementary strain of mRNA. A reference gene hybridization will carried out simultaneously to estimate the relative expression of the gene of interest compared with the reference gene. The new tool we describe here, termed transcriptome array, utilizes cDNA generated from source mRNA for target immobilization to improve the stability of the immobilized targets and differentially fluorescence-labeled test and reference probes (RNA or double strained DNA) then can co-hybridize on to the same spots. Using a validated 
Table 2

\begin{tabular}{|c|c|c|c|c|c|c|}
\hline Gene Name & Image ID & Description & Mean Int & Mean logR & SD $\log R$ & $\%$ of arrays \\
\hline NKTR & 712460 & NK-tumor recognition protein $=c y$ & 7319.55 & 0.62 & 0.79 & 0.52 \\
\hline NKTR & 712460 & NK-tumor recognition protein $=c y$ & 3048.28 & 0.19 & 0.43 & 0.84 \\
\hline NKTR & 712460 & NK-tumor recognition protein $=c y$ & 8637.15 & 0.99 & 0.99 & 0.53 \\
\hline NKTR & 2064497 & natural killer-tumor recognitio & 959.97 & 0.72 & 0.85 & 0.7 \\
\hline PPIC & 882459 & peptidylprolyl isomerase $C$ (cyc & 5034.82 & 2.11 & 1.45 & 0.44 \\
\hline PPIB & 756600 & peptidylprolyl isomerase B (cyc & 6606.09 & 1.08 & 1.04 & 0.39 \\
\hline PPIL2 & 450661 & peptidylprolyl isomerase (cyclo & 3035.17 & 0.16 & 0.4 & 0.85 \\
\hline PPIL2 & 2017652 & peptidylprolyl isomerase (cyclo & 850.93 & 0.23 & 0.48 & 0.76 \\
\hline PPIG & 809621 & peptidyl-prolyl isomerase G (cy & 3991.93 & 0.28 & 0.53 & 0.67 \\
\hline PPID & 884500 & peptidylprolyl isomerase D (cyc & 5805.51 & 0.33 & 0.57 & 0.66 \\
\hline PPID & 71154 & peptidylprolyl isomerase D (cyc & 5652.12 & 0.27 & 0.52 & 0.63 \\
\hline PPIH & 767277 & peptidyl prolyl isomerase $\mathrm{H}$ (cy & 3277.26 & 0.28 & 0.53 & 0.73 \\
\hline PPIF & 758343 & peptidylprolyl isomerase $\mathrm{F}$ (cyc & 15900.53 & 3.18 & 1.78 & 0.13 \\
\hline CYP2J2 & 454580 & cytochrome $\mathrm{P} 450$, family 2 , subf & 2302.76 & 0.71 & 0.84 & 0.65 \\
\hline PPIA & 2580290 & peptidylprolyl isomerase A (cyc & 25478.36 & 1.32 & 1.15 & 0.36 \\
\hline PPIA & $|57086|$ & peptidylprolyl isomerase A (cyc & 5028.34 & 0.76 & 0.87 & 0.46 \\
\hline GAPD & 50117 & glyceraldehyde-3-phosphate dehy & 38011.52 & 1.66 & 1.29 & 0.4 \\
\hline GAPD & 530934 & glyceraldehyde-3-phosphate dehy & 10526.82 & 1.14 & 1.07 & 0.37 \\
\hline GAPD & 530868 & glyceraldehyde-3-phosphate dehy & 5052.59 & 0.81 & 0.9 & 0.25 \\
\hline GAPD & 755641 & glyceraldehyde-3-phosphate dehy & 1693.23 & 0.17 & 0.42 & 0.84 \\
\hline PGKI & 949939 & Phosphoglycerate kinase I & 4452.92 & 0.16 & 0.4 & 0.85 \\
\hline B2M & 878798 & beta-2-microglobulin & 34211.05 & 2.08 & 1.44 & 0.43 \\
\hline AMBP & 2063390 & alpha-I-microglobulin/bikunin $\mathrm{P}$ & 1813.96 & 0.15 & 0.39 & 0.86 \\
\hline GUSB & 2273001 & glucuronidase, beta & 6205.14 & 0.81 & 0.9 & 0.41 \\
\hline GUSB & 276449 & glucuronidase, beta & 2241.73 & 0.22 & 0.47 & 0.68 \\
\hline HPRTI & 280507 & hypoxanthine phosphoribosyltran & $|2778.3|$ & 1.29 & 1.14 & 0.35 \\
\hline TBP & 280735 & TFIID=TATA bo $x$ binding protein & 4065.4 & 0.24 & 0.49 & 0.73 \\
\hline TFR2 & 461750 & transferrin receptor 2 & 2700.22 & 0.19 & 0.44 & 0.84 \\
\hline TFR2 & 2408681 & transferrin receptor 2 & 2958.88 & 0.21 & 0.46 & 0.82 \\
\hline
\end{tabular}

RNA amplification technology [30], large quantity of pure amplified RNA with proportional representation of source mRNA species could be generated from which cDNA could be obtained through a reverse transcription reaction. Because of the minimum amount of cDNA used for fabricating each transcriptome array $(<5$ nano gram cDNA/spot) and the size of spots (100 um), the expression of a large number of genes can be theoretically analyzed on thousands of different samples simultaneously. Since the amount of cDNA spotted may vary according to the quality of the starting material and the efficiency of RNA preparation for each sample, absolute estimation of fluorescence from the hybridized probe is not informative of the expression of the given gene in each sample. Therefore, a reference system is necessary so that comparative expression of the test gene can be presented proportional to that of a consistently expressed gene across all samples. Therefore, interpretation of data derived from the transcriptome array relies on endogenous reference gene normalization.

To test the usefulness of various endogenous reference gene we resorted to the well characterized expression of the melanocytic lineage-specific gene gp 100/Pmel17 [31] that is expressed exclusively though heterogeneously in cells of melanocytic lineage $[35,36]$. The assumption of this experiment was that in spite of its heterogeneity of expression in samples of melanocytic origin, overall the expression of gp100 should be higher in meloanocytic compared with non melanocytic samples with a high degree of significance. Rho-C has been associated with the metastatization process in melanoma but its specificity for melanocytic lineage is unknown [37]. The differentiation control element DICE is found in the 3'-UTR of numerous eukaryotic mRNAs and there is no solid association between its pattern of expression and specific physiopathological or developmental conditions [38]. Therefore, we compared the expression profile of these three genes in 829 cDNA libraries that included 106 melanoma cell lines, 127 melanoma metastases, 2 benign nevi (total of 235 melanocytic samples) and 593 miscellaneous samples containing a predominance of primary esophageal, renal and colon cancers paired with normal tissues from the same organ and a large number of circulating mononuclear cells. In addition, samples from most other normal and cancerous tissues were included although in 
smaller number (complete list of samples available upon request).

As endogenous reference genes we chose $\beta$-Actin and new candidate genes identified by this study (see previous section). The test genes (gp100, Rho-C and DICE) were separately hybridized to the transcriptome array. Each gene labeled with Сy3 was co-hybridized with individual endogenous reference genes labeled with Cy5. We then compared $_{\log 2}$ Cy5 / Cy3 ratios between melanocytic and non-melanocytic tissues. gp100 was, as expected, expressed more in melanocytic lesions with high degree of significance no matter what gp100 / endogenous reference gene combination was used. The range of significance, however, varied extensively depending upon the gp100 / endogenous reference gene combination. This difference was considered representative of the ability of different endogenous reference genes to normalize for tissue-specific gene expression patterns (Figure 1). In details, all endogenous reference genes could segregate melanocytic from non melanocytic lesions with a high degree of significance (Figure 2; unpaired two sample $t$ test $\mathrm{p}_{2}$-values ranged from $6 \times 10^{-8}$ to $3 \times 10^{-36}$ ). There was, however, a big range in the discriminatory capacity among endogenous reference genes with NEDD8, RAB3 and FZD6 providing the highest predictive value $\left(t\right.$ test $\mathrm{p}_{2}$-value $=3 \times 10^{-}$ $36,1 \times 10^{-32}$ and $1 \times 10^{-21}$ respectively) and $\beta$-actin being one of the least reliable $\left(t\right.$ test $\mathrm{p}_{2}$-value $\left.=1 \times 10^{-8}\right)$.

The large variation in the results obtained using different endogenous reference genes to normalize gp100 expression could have been due to a higher stability of the expression of some genes across all samples or to a differential expression of the endogenous reference genes themselves in melanocytic lesion. In the latter case, the better results obtained could be coincidental and not useful in other experimental situations. We, therefore, tested whether pooling results obtained with all endogenous reference genes independently of each predictive value in this controlled experimental situation could yield results as informative about gp100 pattern of expression as those obtainable with individual endogenous reference genes, particularly those that provided the best prediction. The advantage of this strategy is that it does not depend on previous knowledge of gene expression patterns for the selection of individual endogenous reference genes not applicable in conditions, in which the suitability of a gene for a given experimental situation is, contrary to gp 100 , is unknown. Thus, we compared the predictive value of the average of gp100 / endogenous reference gene ${ }_{\text {Log2 }}$ ratios obtained with all endogenous reference genes and those obtained using the genes that provided the best five or the best three results (Figure 2). The use of pooled information from various endogenous reference genes appeared to stabilize the non-melanocytic $\log 2_{2}$ ratios gp100 / endog- enous reference. In fact, the SD of the Log2 $_{2}$ ratios gp100 / endogenous reference among non-melanocytic samples derived by pooling endogenous reference gene results were significantly lower than the SD obtainable with any individual endogenous reference gene (F-test). The basis for this test was that non-melanocytic lesions uniformly should not express gp100 and, therefore, the $\log _{2}$ ratios for any gp100 / endogenous reference gene combination should be constant resulting in very low SD. SD for nonmelanocytic lesions were much lower using pooled endogenous reference genes for the normalization (Figure 2 ) and this was true at extreme levels of significance (F-test value for $\mathrm{SD}$ when all endogenous reference genes were used for normalization compared with individual endogenous reference were $0,1.5 \times 10^{-9}, 0,5.6 \times 10^{-7}, 9.0 \times 10^{-}$ 5, 0, 0, 0 and 0 for NEDD8, RAB3, FZD6, AFAP, COL8A, SNRPD, HIRIP5, $\beta$-actin and GPLD1 respectively). Similar results were obtained when results from the best 5 and best 3 endogenous reference genes were pooled together. In addition, even if pooling data together did not provide the highest level of discrimination compared to the best results obtained with selected individual endogenous reference genes, the capacity of pooled data sets to discriminate gp100 expression between melanocytic and non melanocytic samples was still very high $\left(2 \times 10^{-22} ; 4 \times 10^{-}\right.$ 29 and $1 \times 10^{-34}$ respectively when all, the best 5 or the best 3 endogenous reference gene results were pooled together). Interestingly, different endogenous reference genes provided not only different levels of discrimination but also provided different estimates of gp100 expression in melanocytic lesions with gp 100 / endogenous reference gene Log2 ratio above (NEED8, RAB3, FZD6, AFAP, SNRPD3, HIRIP5, GPLD1) or below (COL8A1, $\beta$-actin) 0 (Bottom graph, Figure 2). This, of course, has no impact on the ability to characterize patterns of expression of different genes in different tissues but rather suggests that the latter group of endogenous reference genes is expressed at higher copy number, therefore, biasing the data toward its own fluorescence channel. Simple adjustment in probe concentration could easily solve this problem.

We then analyzed the expression of Rho-C and DICE whose pattern of expression in the transcriptome array cannot be predicted based on available information save for the notion that of the expression of Rho-C is related to the metastatic process of melanoma [37]. The pattern of Rho-C was characterized with all the endogenous reference genes and representative information is presented in Figure 3. Most endogenous reference genes yielded a pattern suggestive of a preferential expression of Rho-C in melanoma metastases. In addition, averages of Rho-C / endogenous reference gene ${ }_{\text {Log } 2}$ ratios demonstrated clearly a specific expression of this gene in melanoma metastases. This pattern was not necessarily specific for melanoma as the other cancerous tissues 

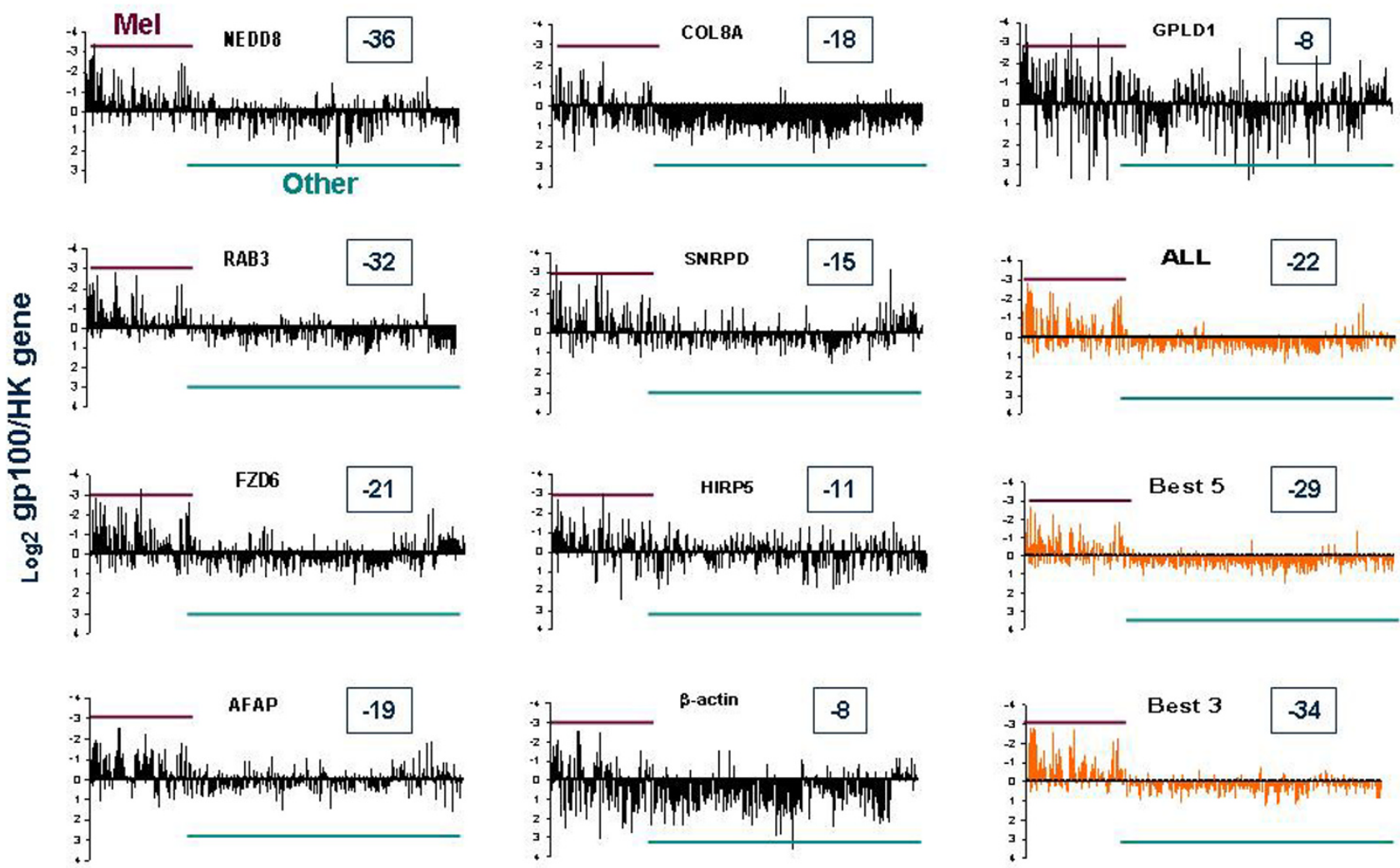

\section{Figure I}

Comparison of gp 100 expression normalized by different endogenous reference genes. Candidate endogenous reference genes were selected among those in Table I. The gp 100 probe (Cy3) was co-hybridized with one endogenous reference gene probe (Cy5) at the time to the transcriptome array. The transcriptome array included 235 cDNA libraries derived from samples of melanocytic lineage (maroon bar) and 594 cDNA libraries from samples of non melanocytic lineage (green bar). Melanocytic samples consisting in the overwhelming majority of melanoma metastases or melanoma cell lines while non-melanocytic libraries included a large collection of esophageal, kidney, colon and other cancers and several normal tissues or circulating mononuclear cells. The complete list of samples is available upon request. The expression of gp 100 normalized with different endogenous reference genes was compared by unpaired two-tailed student $t$ test and the endogenous reference genes were ranked according to the level of significance in their ability to discriminate between melanocytic and non-melanocytic lesions (data presented as the $\log _{10} \mathrm{P}_{2}$-value (shown in the boxes associated with individual graphs; for details see Figure 2). The distribution of the $\log 2_{2}$ ratios for each individual CDNA library is shown for each gp 100 / endogenous reference gene combination. In addition, results compiled using the average of the $\log 2_{2}$ ratios for all the endogenous reference genes, the 5 and the 3 with the lowest $\mathrm{p}_{2}$-value are presented (orange bar graphs).

spotted in the transcriptome array were obtained from primary lesions. Thus, it is possible that the preferential expression in melanoma metastases was due to the metastatic process rather than the melanocytic lineage. Interestingly, the melanoma cell line Mel-A375 did not constitutively express Rho-C as previously observed by Clark et al. [37]. In addition, none of the melanoma cell lines mostly derived from melanoma metastases demonstrated expression of Rho-C. This information suggests that Rho-C may be involved in the natural metastatic 


\section{Expression of gp100 relative to different house keeping (HK) genes}

\begin{tabular}{|c|c|c|c|c|c|c|c|c|c|c|c|c|}
\hline Mean goroo'hk cene & NEDD8 & RAB3 & FZD6 & AFAP & COL8A & SNRPD & HIRIP5 & $\beta$-actin & GPLD1- & ALL & Best 5 & Best 3 \\
\hline Melanoma (n-235) & -0.58 & -0.44 & -0.54 & -0.42 & 0.32 & -0.40 & -0.32 & 0.24 & -0.41 & -0.28 & $\mathbf{0 . 3 3}$ & -0.52 \\
\hline $\mathrm{SD}$ & 0.81 & 0.76 & 0.96 & 0.80 & 0.89 & 0.90 & 0.86 & 1.15 & 1.56 & 0.83 & 0.77 & 0.78 \\
\hline SEM & 0.05 & 0.05 & 0.06 & 0.05 & 0.06 & 0.06 & 0.06 & 0.08 & 0.10 & 0.05 & 0.05 & 0.05 \\
\hline Non Mel $(n=594)$ & 0.25 & 0.27 & 0.14 & 0.11 & 0.88 & 0.12 & 0.11 & 0.72 & 0.21 & 0.31 & 0.33 & 0.22 \\
\hline $\mathrm{SD}$ & 0.61 & 0.46 & 0.55 & 0.44 & 0.42 & 0.55 & 0.69 & 0.81 & 1.02 & 0.36 & 0.33 & 0.37 \\
\hline SEM & 0.02 & 0.02 & 0.02 & 0.02 & 0.02 & 0.02 & 0.03 & 0.03 & 0.04 & 0.01 & 0.01 & 0.02 \\
\hline $\log _{10}$ t-test $p_{2}$-value & -36 & 32 & -21 & -19 & -18 & -15 & -11 & 8 & -8 & -22 & -29 & -34 \\
\hline
\end{tabular}

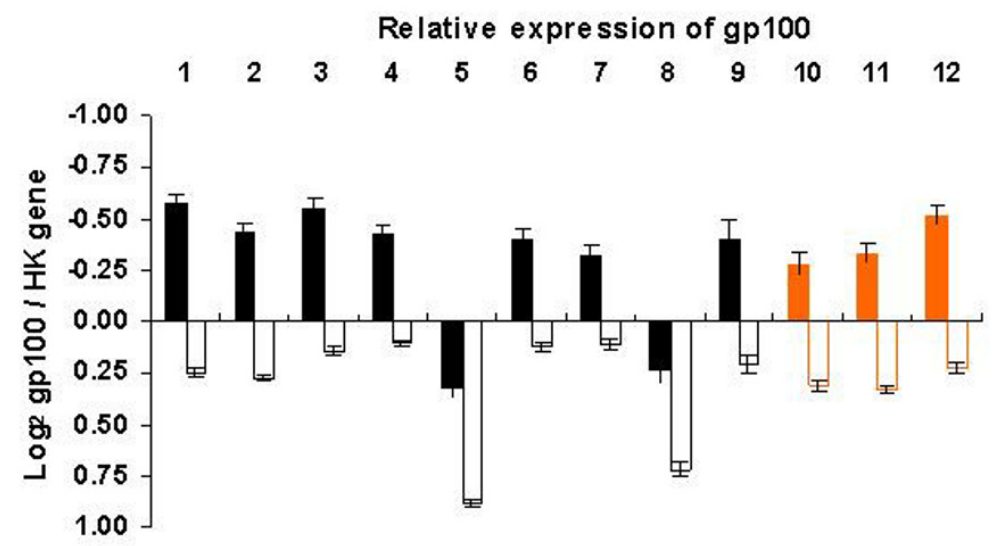

\section{Figure 2}

Expression of gpl00 by melanocytic and non melanocytic lesions normalized with different endogenous reference genes. Average gp 100 / endogenous reference gene $\log 2_{2}$ ratios for melanocytic and non-melanocytic lesions are shown together with the standard deviation (SD) standard error from the mean (SEM) and the $\log _{10}$ of the $t$-test $P_{2}$-values when melanocytic and nonmelanocytic lesions were compared. Also data derived from mathematically averaging the results obtained with all the endogenous reference genes, the ones yielding the best 5 individual $p_{2}$-values and the best three are shown. The same data are presented visually in the bar graph below; in black are data derived with individual endogenous reference gene normalizations, in orange data derived by averaging results from different endogenous reference genes. Filled bares portrait data from melanocytic lesions, empty bars from non-melanocytic lesions.

process in vivo but is not constitutively expressed in vitro. Finally, DICE did not demonstrate any specificity of expression and appeared variably expressed in all specimens independently of the endogenous reference gene used for normalization.

\section{Validation of data by protein analysis and quantitative real-time PCR (qRT-PCR)}

We tested whether gp100 / endogenous reference gene Log2 $_{2}$ ratios correlated with gp100 protein expression level as measured by intra-cellular FACS analysis (Figure 4). The gp100 / endogenous reference gene $\log _{2}$ ratios were derived from the transcriptome arrays while protein expression was based on previous characterizations of the same cell lines [35,39]. Overall, a good correlation (Pearson's correlation) was noted for gp100 values normalized with most endogenous reference genes. However, with the exception of NEDD8, the best correlation was obtained when pooled information was used from the best 5 and 3 candidate endogenous reference genes as defined before. 


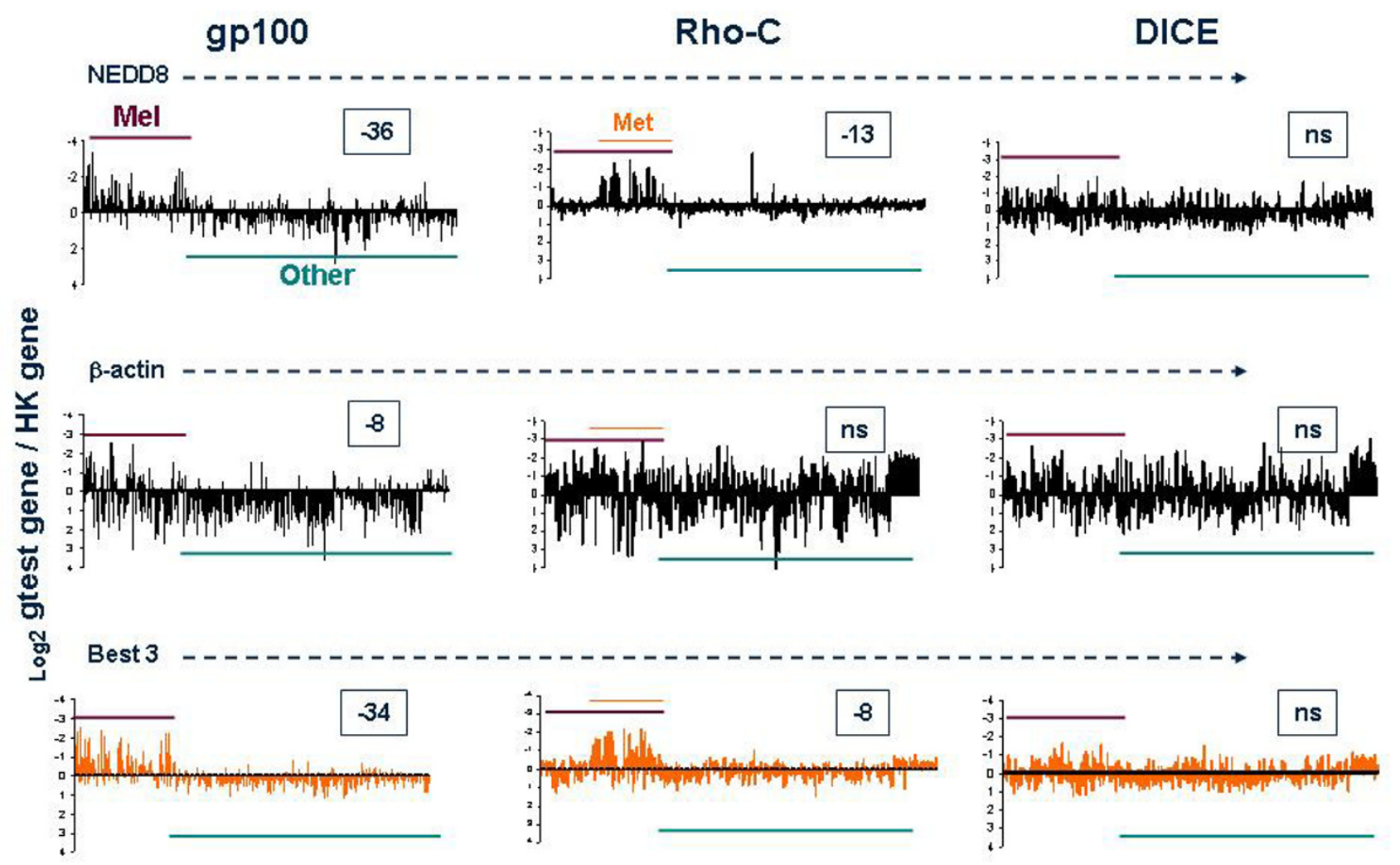

Figure 3

Relative expression of gp I00, Rho-C and DICE in melanocytic and non-melanocytic samples. Test samples (Cy3) and endogenous reference genes (Cy5) were hybridized to the transcriptome array as described in Figure I. Test gene / endogenous reference gene $\log _{2}$ ratios are displayed as a bar graph for NEED8, $\beta$-actin and for the averages of test / endogenous reference gene $_{\text {Log } 2}$ ratios when the three endogenous reference genes with the best discriminating power in separating gP 100 expression between melanocytic (maroon bar) and non-melanocytic (green bar) lesions (NEDD8, RAB3 and FZD6) were used. Samples derived from melanoma metastases are shown by the orange bar. In the boxes the $\log 10 \mathrm{P}_{2}$-value of significance of differences between relevant samples (se text) are shown; $\mathrm{ns}=$ non significant).

Interestingly, RAB3 that scored very high as a predictor of gp100 transcriptional expression in melanocytic lesions and $\beta$-actin provided the worst correlation with protein expression. This data suggest that, although different endogenous reference genes may yield better predictive value than others in large data sets, it is likely that their reliability varies in different conditions and possibly the best results can be obtained by pooling information from several of them.
We also tested by quantitative real-time PCR (qRT-PCR) the discriminatory capacity of endogenous reference genes in samples with known patterns of expression of gp100. We selected 6 previously characterized $[35,36]$ melanoma cell lines four of which were known to express (MEL-553B, MEL-1317, MEL-526, MEL-1102) and two known not to express (MEL-836, MEL-1195) gp100 at the transcriptional and protein level (Figure 5) [36,39]. In addition, 4 fine needle aspirate (FNA) samples from 


\section{Correlation of gp100 expression by immunological methods and gene profiling}

\begin{tabular}{|c|c|c|c|c|c|c|c|c|c|c|c|c|c|}
\hline & MEF & NEDD8 & Best 5 & Best 3 & COL8A1 & AFAP & All & FZD6 & SNRPD3 & HIRIP5 & GPLD1-2 & RAB3 & $\beta$-actin \\
\hline Mel-1102 & 250.0 & -0.9 & -0.7 & -0.8 & 0.0 & -0.9 & -0.6 & -1.0 & -0.6 & -0.8 & -1.0 & -0.7 & 0.1 \\
\hline Mel-526 & 215.0 & -0.8 & -0.9 & -0.9 & -0.2 & -1.3 & -1.0 & -1.1 & -0.9 & -1.4 & -1.8 & -1.0 & -0.9 \\
\hline Mel-1182 & 198.0 & -0.4 & -0.1 & -0.3 & 0.8 & -0.4 & -0.2 & -0.3 & -0.1 & -0.9 & -0.5 & -0.3 & 0.4 \\
\hline Mel-938 & 113.0 & -0.2 & 0.0 & -0.2 & 0.8 & -0.1 & 0.2 & 0.0 & 0.4 & -0.2 & 0.6 & -0.3 & 1.0 \\
\hline Mel-624 & 109.0 & -0.7 & -0.8 & -0.9 & -0.2 & -0.9 & -0.8 & -1.2 & -0.7 & -0.7 & -1.3 & -0.9 & -0.3 \\
\hline Mel-1173 & 101.0 & -0.9 & -0.6 & -0.8 & 0.1 & -0.8 & -0.8 & -0.7 & -0.7 & -1.2 & -1.6 & -0.7 & -0.6 \\
\hline Mel-888 & 78.5 & -0.4 & -0.6 & -0.7 & 0.1 & -1.0 & -0.7 & -1.0 & -0.7 & -0.8 & -1.4 & -0.9 & -0.3 \\
\hline Mel-883 & 48.0 & -0.1 & -0.5 & -0.6 & 0.4 & -1.0 & -0.6 & -0.7 & -0.6 & -0.9 & -1.4 & -0.9 & -0.4 \\
\hline Mel-1195 & 2.0 & -0.1 & 0.5 & 0.1 & 1.9 & 0.5 & 0.4 & 0.4 & 0.9 & -1.0 & 0.0 & -0.2 & 1.0 \\
\hline Mel_A375 & 1.0 & 0.0 & 0.2 & -0.1 & 1.2 & 0.0 & 0.2 & -0.1 & 0.0 & 0.3 & 0.1 & -0.1 & 0.1 \\
\hline Mel-537 & 1.0 & 0.3 & 0.5 & 0.4 & 1.0 & 0.2 & 0.6 & 0.4 & 0.7 & 0.1 & 0.9 & 0.3 & 1.2 \\
\hline Spearman rank & 1.0 & 0.8 & -0.6 & 0.6 & -0.6 & 0.5 & 0.5 & -0.5 & -0.5 & -0.4 & -0.4 & -0.4 & -0.2 \\
\hline & & & & & & & & & & & & & \\
\hline
\end{tabular}

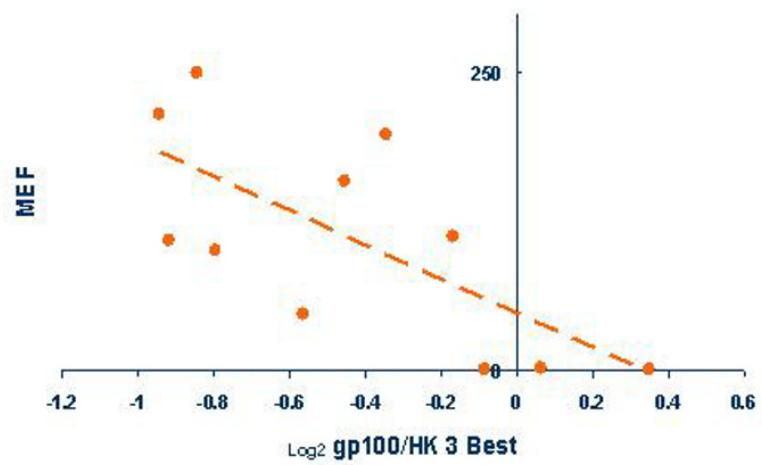

\section{Figure 4}

Correlation of gp 100 expression estimated obtained by intracellular FACS analysis and by gene profiling with the transcriptome array. Cell lines with different level of gp 100 expression by intra-cellular FACS analysis using the gp I00-specific mAb HMB45 [35] were used for the analysis. The compiled information from the transcriptome array in which cDNAs from each cell line was spotted are shown. The Cy5/Cy3 (endogenous reference gene / gP I00) Log2 ratios are shown for each endogenous reference gene evaluated. In addition, ratios derived by using the data from all the endogenous reference genes, the best 5 and best 3 according to figure 2 are also presented. Pearson's correlation for the data set is shown for each endogenous reference gene and the same information is summarized graphically at the bottom of the figure. MEF = mean equivalent of fluorescence [35].

melanoma metastases expressing gp100 [40] and a series of tumors ( 2 renal cell, 2 esophageal one gastric carcinomas and HELA cells line) known not to express gp100 were tested. Absolute expression of gp100 was measured and although the lesions supposed to be gp100 expressing appeared more positive than those supposed to be gp100 negative there was no absolute demarcation among the two groups (Figure 5a). A better differentiation between positive and negative lesions could be obtained when the various endogenous reference genes were used for the analysis or the combined values from all of them (Figure $5 b)$.

\section{Discussion}

Although the concept of endogenous reference genes is appealing it may be unrealistic to expect that a gene could be equally expressed in all eukaryotic cells in all physiopathological conditions. Thus, the endogenous reference gene concept can only approximate such ideal biological behavior. In fact, numerous studies noted that the 


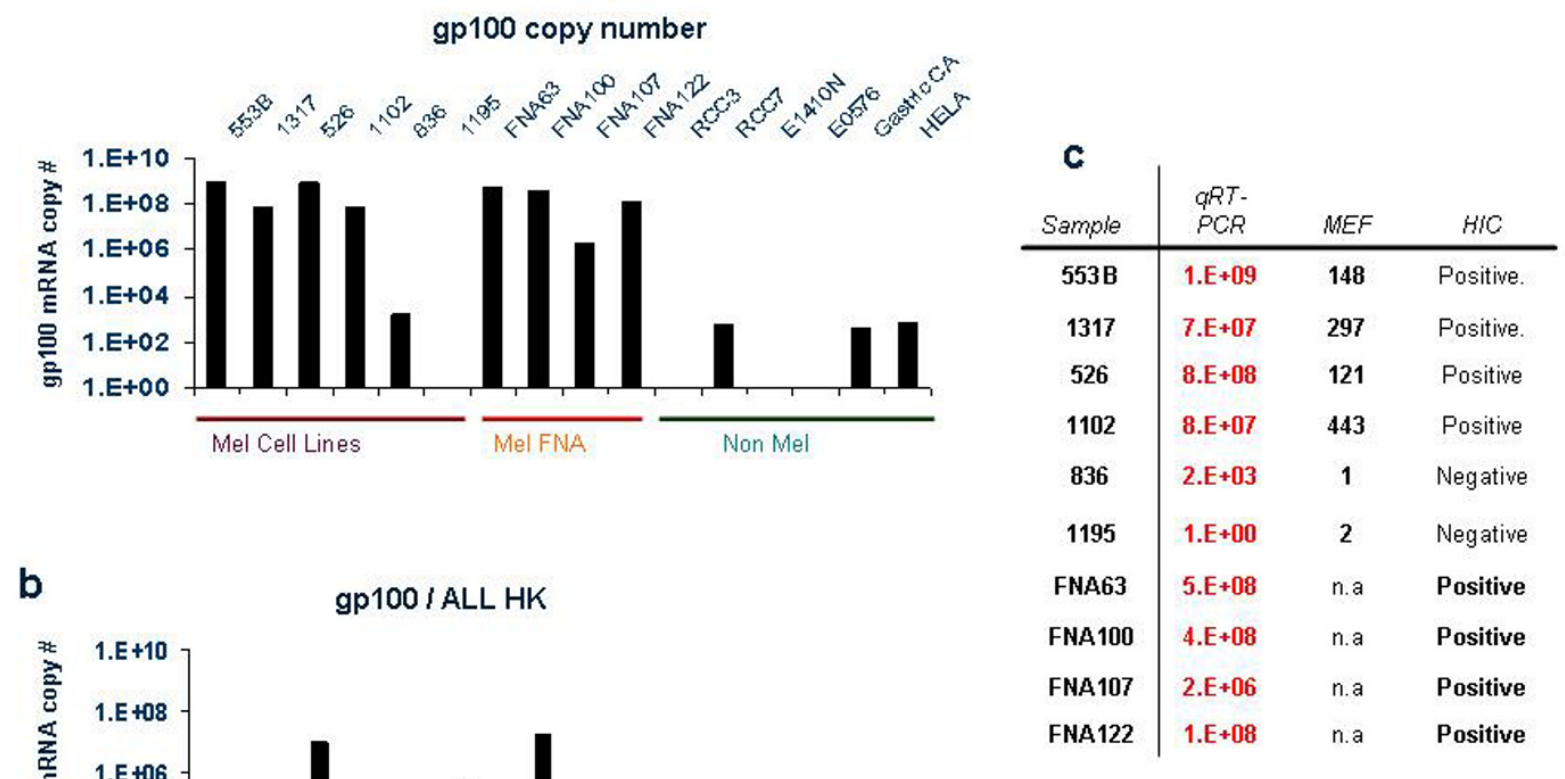

Figure 5

Absolute and normalized expression of gp 100 based on qRT-PCR. Four melanoma cell lines expressing gP I00 (MEL-553B, MEL I 3 I 7, MEL 526 and MEL-I I02) and 2 not expressing gp I00 (MEL-836 and MEL-I 195) protein by FACS analysis [35] (maroon horizontal bar) were tested for gp 100 expression by QRT-PCR as previously described [40]. In addition four fine need aspirates of melanoma metastases all expressing GPI00 by immunohistochemistry (orange horizontal bars) and two renal cell, two esophageal and one gastric cancer specimens all not expressing gp 100 (green horizontal bar) were tested. Similarly the gp 00 not expressing HeLa cell line was tested. Absolute gp 100 copy number is shown in (a); normalized expression of gp I00 is shown using the average of all endogenous reference gene results (b). The protein expression for the melanoma cell lines is presented as mean equivalent of fluorescence (MEF) [35] as well as immunohistochemical evaluation while the expression by FNA is shown in (c) based on immunohistochemical (HIC) evaluation as previously described [46]. Absolute copy numbers of gPl00 estimated by qRT-PCR are also shown.

expression of the ostensible endogenous reference genes varies according to distinct physio-pathological situations and can be affected by experimental manipulation $[2,20,24,26,27,41]$. For instance, the levels of expression of GAPDH, cyclophilin and $\beta$-actin fluctuate in different tissues, disease stage and are affected by cell behavior like proliferation $[6,15,18,20,42]$. In addition, endogenous reference genes expression varies markedly in cancer com- pared to normal tissue $[17,26,41]$ suggesting that oncogenesis may influence their expression [25].

In this study, therefore, we looked for relative stable endogenous reference gene challenging a 17,000 cDNA clone data base against approximately 400 specimens that included a broad variety of normal and neoplastic tissues as well as cell lines. Indeed, few previously unnamed 
genes approximated the ideal endogenous reference gene by being expressed consistently in more than $95 \%$ of the specimens analyzed within a variance that was barely and insignificantly different from what could be expected from intrinsic experimental fluctuation (Table 1). In fact, the threshold that we selected based on the variance observed by periodically repeating identical experiments was consistent with criteria suggested by others [43] who claimed that genes with fold changes greater than 1.5 can be classified as differentially expressed at $95 \%$ confidence interval. This is consistent to our selection criterion that contained endogenous reference genes within a 1.46 fold maximal variation. Although these genes have not been proposed before as candidate endogenous reference genes, analysis of available data bases suggested that they are relatively stably expressed in various normal tissues (i.e. Affymetrix HG-U95A-E probe sets). Selection of these candidate endogenous reference genes provided useful information when the expression of a lineage specific gene such as gp100 was compared between relevant and irrelevant samples. In addition, gp100 expression normalized according to some of the new endogenous reference genes more closely aligned to lineage specificity than normalization performed using $\beta$-actin.

This data, however, confirm that there is no such thing as a perfect endogenous reference gene. Although some endogenous reference genes demonstrated high power of discrimination their ranking was dictated by previous knowledge of the expected experimental results (gp100 being melanocytic lineage specific). However, gene expression analysis is done to determine such specificity and in most cases no previous knowledge of tissue specificity is truly available. One may argue that, in spite of the extreme variability in normalization power demonstrated by various endogenous reference genes, still significant differences could extracted between the melanocytic and non-melanocytic samples no matter what endogenous reference genes were used. This statement is correct in this experimental situation where hundreds of samples could be compared with the transcriptome array. However, in cases when only few samples are analyzed the difference in discriminatory capacity becomes critical. For instance, when randomly selected gp100 / endogenous reference gene $_{\mathrm{Log} 2}$ ratios from 10 melanoma metastases were compared with those from 10 kidney specimens only NEDD8, RAb3, FZD6, AFAP, COL8, SNRPD and pooled endogenous reference gene-based normalizations yielded significant differences between the two groups while non significant values were obtained for normalizations based on HIRIP5, $\beta$-actin and GPLD1.

The lowest limit of detection in the transcriptome array of specific probes in term of copy numbers is currently under investigation. Decreasing concentrations of $\beta$-actin alone printed the array spots as internal controls suggest that the detection range is from $30 \mathrm{ng} /$ spot to $3 \mathrm{pg} /$ spot when standard fluorescent intensity range parameters are applied. The higher limit of detection before saturation can be easily adjusted to avoid under estimates of highly expressed genes, therefore, increasing the dynamic range of detection. This is achieved by adjusting the fluorescent intensity right below the saturation for both channel and subsequently calculating the abundance of reference gene expression using serially diluted internal control spots as standard curve. With few exceptions, the expression of most genes can be estimated with relative accuracy using this semi-quantitative approach.

Since in most cases endogenous reference genes are selected based on previous knowledge of their usefulness for a particular experimental situations, it is likely that the best consistency could be achieved in such circumstances when averages of several endogenous reference gene normalizations are used. This may represent a reasonable solution particularly if a cocktail of endogenous reference genes identically labeled could be used as reference within a single experiment. We are presently testing various combinations of lineage specific genes and pools of endogenous reference genes for hybridization to the transcriptome array and for qRT-PCR. Such attempts, however, have been quite disappointing so far as results obtained using mixture of endogenous reference genes do not yield information comparable to that achievable when results obtained with the same endogenous reference genes used individually are pooled together. This is possibly due to imbalanced density of various endogenous reference genes in different samples with predominant effects of some over others. Therefore, extensive work in the future will be aimed at equilibrating the interactions among endogenous reference genes in various experimental conditions to test whether mixtures of them could be used in multiplex for normalization of large expression analysis studies.

\section{Conclusions}

Our observations, together with previous work by others indicate that much caution should be taken when using endogenous reference to normalize the expression of test genes. It is likely that previous analyses based on single endogenous reference genes might have been strongly biased by the individual selections and the interpretation of the results should looked at with caution. In particular, this study suggests that even when the most stably expressed genes in array experiments are used as endogenous reference genes, significant variation in test gene expression estimates may occur and the best normalization is achieved when data from several endogenous reference genes are pooled together to minimize minimal but significant variation among samples. We are presently 
optimizing strategies for the preparation of endogenous reference gene mixtures that could yield information comparable to that of data pooled from individual endogenous reference gene normalizations.

\section{Methods}

The list of samples used for cDNA microarray hybridization or for preparation of the transcriptome array is available upon request. Most melanoma and renal carcinoma cell lines were generated at the Surgery Branch, National Cancer Institute (NCI), National Institutes of Health (NIH), Bethesda, MD and maintained in RPMI (Biosource International, Camarillo, CA) supplemented with $10 \%$ fetal calf serum (Biosource). Cell lines were harvested by Trypsin /Versene (Biosource) digestion. PBMC were collected by leukapheresis from six unrelated normal donors in the Department of Transfusion Medicine, Clinical Center, NIH and purified by Ficoll gradient separation. Surgically removed tumor tissues were collected from the Tissue Network (Philadelphia, PA), Surgery Branch and CPSB specimen bank, NCI, (Bethesda, MD). Fine needle aspiration (FNA) biopsies were obtained from patients with metastatic melanoma referred to the Surgery Branch, NCI for immunotherapy. Total RNA was isolated using Qiagen RNeasy kit and its quality and quantity was estimated using Agilent Bioanalyzer 2000 (Agilent Technologies, Palo Alto, CA).

\section{Target preparation for cDNA microarray hybridization}

Total RNA extracted from test and reference samples was transcribed in vitro into anti-sense RNA (aRNA) and reverse-transcribed into fluorescence labeled cDNA for hybridization to 17,000 gene cDNA-based microarrays $[30,44]$. Pooled PBMC were used to prepare reference aRNA to be co-hybridized in all experiments with test aRNA. cDNA targets were labeled with Cy3 (green) for reference material and Cy5 (red) for test material with the exception of reciprocal experiments.

\section{cDNA Microarrays}

cDNA (UniGene cluster) microarrays were printed at the Immunogenetics Section, DTM, CC, NIH with a configuration of $32 \times 24 \times 23$ containing 17,500 elements. Clones used for printing were selected from the Research Genetics RG_HsKG_031901 $8 \mathrm{k}$ clone set and the 9k RG_Hs_seq_ver_070700 $40 \mathrm{k}$ clone set. The 17,500 spots included 12,072 uniquely named genes, 875 duplicate genes and about 4,000 expression sequence tags. For a complete list of genes included in the Hs-CCDTM-17.5k$1 \mathrm{px}$ printing please visit our web site at http://nci array.nci.nih.gov/gal files/index.shtml.

\section{Transcriptome array}

A collection of aRNA-based libraries was prepared from 960 frozen tissue samples or cell lines and individual
aRNAs were reverse transcribed into cDNA in the presence of $1 \mu \mathrm{l}$ of dN 6 primer $(8 \mu \mathrm{g} / \mu \mathrm{l}), 6 \mu \mathrm{l}$ of first strand buffer, $3 \mu \mathrm{l}$ of $10 \mathrm{mM}$ dNTP, 3 ul of $50 \mathrm{mM}$ dTT, $1.5 \mu \mathrm{l}$ of Rnasin and $10 \mu \mathrm{l}$ of aRNA (6-12 ug) with addition of $3 \mu \mathrm{l}$ of Superscript II (BRL) in $5.5 \mu \mathrm{l}$ volume after heating to $65^{\circ} \mathrm{C}$ for 5 minutes. Reactions were carried out in 96-well plates at $42^{\circ} \mathrm{C}$ for 90 minutes followed with addition of 1 $\mu \mathrm{l}$ Rnase $\mathrm{H}$ and heating for $20 \mathrm{~min}$ at $37^{\circ} \mathrm{C}$. cDNA were further purified by utilizing CentriCept gelfitration plates to remove non incorporated primer and dNTP. Purified cDNA were transferred to 384-well plates and dried by speedvac. Samples were re-suspended in $13 \mu$ l of $3 \times$ SSC followed by shaking at 3,000 rpm for $15 \mathrm{~min}$. Reconstituted cDNA libraries from individual samples and spiked reference gene at different concentration were printed on to poly-L-lysine coated glass slides at the concentration of $0.5-1 \mu \mathrm{g} / \mu \mathrm{l}$ using the OmniGrid (GeneMachine. San Carlos, CA) printer and Telechem printing pins (TeleChem International, Inc. Sunnyvale, CA). Each $100 \mu$ m diameter spot was duplicated at a $250 \mu \mathrm{m}$ distance. After complete exsiccation, slides were post-processed as described at http://nciarray.nci.nih.gov/reference/

Post Processing.html.

\section{Probe design Transcriptome array hybridization experiments}

Specific PCR primers for the amplification of each gene probe were designed using Primer 3 program http://mol bio.info.nih.gov/molbio/analysis.htm. In order to generate single strand fluorescence labeled cDNA for hybridization, modified specific 5 ' primers with an extension of the T7 promoter region were used for PCR amplification. Double strand PCR fragments (300-800 bp) were used as template for in vitro transcription to generate single stranded mRNA. $3 \mu \mathrm{g}$ of amplified RNA were then reverse transcribed into cDNA in present of $4 \mu \mathrm{l}$ of first strand buffer, $1 \mu \mathrm{l}$ dN6 primer $(8 \mu \mathrm{g} / \mu \mathrm{l}$; Boehringer Mannheim), $2 \mu \mathrm{l} 10 \mathrm{X}$ low T-dNTP (5 mM A, C and GTP, $2 \mathrm{mM}$ dTTP), $2 \mu$ l Cy-dUTP ( 1 mM, Cy3 or Cy5), $2 \mu$ l 0.1 M DTT, $1 \mu$ R Rasin, $3 \mu \mathrm{g}$ amplified mRNA in $8 \mu \mathrm{l}$ DEPC $\mathrm{H}_{2} \mathrm{O}$. After heating to $65^{\circ} \mathrm{C}$ for 5 minutes and cooling to $42^{\circ} \mathrm{C}$, $2 \mu \mathrm{l}$ of SSII was added and the labeling reaction was carried out at $42^{\circ} \mathrm{C}$ for $90 \mathrm{~min}$. Probe purification and hybridization were performed as previously described $[30,44]$.

\section{Quantitative real-time polymerase chain reaction (RT- PCR)}

Primer and probe sets from each candidate genes were designed using the Primer Express 2.0 program (Applied Biosystems, Foster City, CA) and synthesized by BioSource. Taqman probes were labeled at the 5 ' end with the reporter dye molecule 6-carboxy-fluorescein (FAM; emission $\lambda_{\max }=518 \mathrm{~nm}$ ) and at the $3^{\prime}$ end with the quencher dye molecule 6-carboxytetramethyl-rhodamine (TAMRA; 
Table 3: Quantitative RT-PCR primers and probes

\begin{tabular}{|c|c|c|}
\hline \multirow[t]{3}{*}{ AFAP } & $(+)$-TGTCAAGTTAAACCACTAATGTGTTGGT & $Y=-3.105 x+43.726 R 2=0.99$ \\
\hline & (-)-GGCATCCAAATTCTCCAAGAAA & \\
\hline & FAM-TGCTGCCTCTCCTGAGTAGGGTGGGT-TAMRA & \\
\hline \multirow[t]{3}{*}{ CDK5RI } & $(+)$-TCCTACATGGGCAACGAGATC & $Y=-3.315 x+45.983 R 2=0.99$ \\
\hline & (-)-CCAAAAGGCCTCCTTGCA & \\
\hline & FAM -TACCCGCTCAAGCCCTTCCTGGTG -TAMRA & \\
\hline \multirow[t]{3}{*}{ COL8AI } & $(+)-C C G A G C T A A C C G C A C C T T T$ & $Y=-3.143 x+43.294 R 2=0.99$ \\
\hline & (-)-GTCTGCGGGTTGTAGTTCTGTCT & \\
\hline & FAM -AGTGAAGTTTAACAAACTGCTGTATAACGG -TAMRA & \\
\hline \multirow[t]{3}{*}{ FZD } & $(+)$-AGCCTCAAAGGTTCCACATCTC & $Y=-3.515 x+47.092 R 2=0.99$ \\
\hline & (-)-AGGTCACTTCCAGTGTAACACAAATT & \\
\hline & FAM -TGAGAAAAGAGCAGGGAGGTGGTTGTCA -TAMRA & \\
\hline \multirow[t]{3}{*}{ GPLDI-I } & $(+)$-CAGATTGAAGATTTCACTGCATTTC & $Y=-3.653 x+49.086 R 2=0.99$ \\
\hline & (-)-CATCAAAATGCTCACCATGGA & \\
\hline & FAM -TCTGCCСACСTCTCTCATGCTGAATCAC -TAMRA & \\
\hline \multirow[t]{3}{*}{ GPLDI-2 } & $(+)$-CTTTTGCCTGTAGTAGTAAATTGCTTTTA & $Y=-3.168 x+46.599 R 2=0.99$ \\
\hline & (-)-AACTGGCCATATAAC CAAAGGTGTT & \\
\hline & FAM -TGAATGGTGTTTATTAAACCCTTATGGTCGATATTTCC-TAMRA & \\
\hline \multirow[t]{3}{*}{ HIRIP5 } & $(+)$-GCTGCCCTAGTTCAATCATTACTCT & $Y=-3.160 x+43.313 R 2=0.99$ \\
\hline & (-)-CGCCTTCTACCTCCGGAATAT & \\
\hline & FAM - AAAAATGGAATTCAGAACATGCTGCA-TAMRA & \\
\hline \multirow[t]{3}{*}{ HISTIHIA } & $(+)$-AGGCGTCCTCCGTGGAA & $Y=-3.143 x+43.294 R 2=0.99$ \\
\hline & (-)-ATGCACCCGTTGCCTTAGTT & \\
\hline & FAM - AGCCCGGCGCCTCAAAGGTG-TAMRA & \\
\hline \multirow[t]{3}{*}{ NEDD8 } & $(+)$-TGACCGGAAAGGAGATTGAGA & $Y=-3.458 x+48.686 R 2=0.99$ \\
\hline & (-)-CCACACGCTCCTTGATTCG & \\
\hline & FAM - TGACATTGAACCTACAGACAAGGTGGA-TAMRA & \\
\hline \multirow[t]{2}{*}{ PTH } & $(+)$-GCATAACCTGGGAAAACATCTGA & $Y=-3.063 x+45.215 R 2=0.99$ \\
\hline & $\begin{array}{l}\text { (-)-TGCACATCCTGCAGCTTCTT } \\
\text { FAM -TCGATGGAGAGAGTAGAATGGCTGC-TAMRA }\end{array}$ & \\
\hline \multirow[t]{3}{*}{ RAB3I } & $(+)$-CCCCTGAAGGATGCTAAGGAA & $Y=-3.303 x+48.517 R 2=0.99$ \\
\hline & (-)-AGCATTTTTTGCACTTGTCTCAAC & \\
\hline & FAM - ACGCTGAATCCATAGGTGCCATC-TAMRA & \\
\hline \multirow[t]{3}{*}{ SNRPD3 } & $(+)$-GGCACAGCTGGAGCAGGTAT & $Y=-3.177 x+47.200 R 2=0.99$ \\
\hline & (-)-CTTCAGCATGTCAGGCAAAATC & \\
\hline & FAM - ATCCGTGGCAGCAAAATCCGC -TAMRA & \\
\hline \multirow[t]{3}{*}{$\beta$-actin } & $(+)$-GGCACCCAGCACAATGAAG & $Y=-3.127 x+44.733 R 2=0.99$ \\
\hline & (-)-GCCGATCCACACGGAGTACT & \\
\hline & FAM-TCAAGATCATTGCTCCTCCTGAGCGC-TAMRA & \\
\hline \multirow[t]{3}{*}{ gp 100} & $(+)$ GGTTCCTTTTCCGTCACCCT & $Y=-3.282 x+45.987 R 2=0.99$ \\
\hline & (-)CTCACCGGACGGCACAG & \\
\hline & FAM-ACATTGTCCAGGGTATTGAAAGTGCCGAGAT-TAMRA & \\
\hline
\end{tabular}

emission $\lambda_{\max }=582 \mathrm{~nm}$ ). Total RNA was used for gene expression validation. Measurement of gene expression was performed using the ABI 7900HT sequence detection system (Perkin Elmer, Foster City, CA) as previously described $[40,45]$. Messenger RNA from test samples were reverse transcribed into $\mathrm{CDNA}$ in the presence of oligo $\mathrm{dT}$ (12-18 mer). The qRT-PCR procedure was performed by alternating 2 minute cycles at $50^{\circ} \mathrm{C}$ and 10 minute at $95^{\circ} \mathrm{C}$. Forty cycles involving denaturation at $95^{\circ} \mathrm{C}$ for 15 seconds and annealing/extension at $60^{\circ} \mathrm{C}$ for 1 minute in $50 \mu$ volume with $1 \times$ TaqMan Master Mix (PerkinElmer). Standard curves were generated for each gene with high and accurate PCR amplification efficiency as determined by the slope of the standard curves. Linear regression anal- ysis of all standard curves documented in all cases an $\mathrm{R}$ value $\geq 0.99$. The sequence of primer sets and probes used for each gene are shown in Table 3 with statistics for each standard curve. Standard curve extrapolation of copy number was performed for the gene of interest as well as an endogenous reference gene for each sample. To correct for concentration of starting material, normalization of samples was performed by dividing the copies of the gene of interest by copies of the reference gene as previously described [40].

\section{Authors' contributions}

PJ validated the system combining high-throughput data with gene-directed analysis by quantitative real-time PCR. 
YZ performed statistical analysis. YN, MCP, DN, VM and KS participated in the preparation and utilization of array experiments used for the identification of stably expressed genes. $\mathrm{NH}, \mathrm{HS}$ and PRT provided a large library of samples necessary for the development of the transcriptome array. FMM supervise the project as principal investigator.

EW provided leadership for the development of cDNA arrays, transcriptome array and for the overall conduct of the experiments.

\section{References}

I. Thellin O, Zorzi W, Lakaye B, De Borman B, Coumans B, Hennen G, Grisar $T$, lgout $A$, Heinen $E$ : Housekeeping genes as internal standards: use and limits. J Biotechnol 1999, 75:291-295.

2. Sturzenbaum SR, Kille P: Control genes in quantitative molecular biological techniques: the variability of invariance. Comp Biochem Physiol B Biochem Mol Biol 200I, I 30:28I-289.

3. Gorzelniak K, Janke J, Engeli S, Sharma AM: Validation of endogenous controls for gene expression studies in human adipocytes and preadipocytes. Horm Metab Res 200I, 33:625-627.

4. Petersen BH, Rapaport R, Henry DP, Huseman C, Moore WV: Effect of treatment with biosynthetic human growth hormone (GH) on peripheral blood lymphocyte populations and function in growth hormone-deficient children. J Clin Endocrinol Metab 1990, 70:I756-I760.

5. Tang WW, Qi M, Van GY, Wariner GP, Samal B: Leukemia inhibitory factor ameliorates experimental anti-GBM Ab glomerulonephritis. Kidney Int 1996, 50:1922-1927.

6. Goldsworthy SM, Goldsworthy TL, Sprankle CS, Butterworth BE: Variation in expression of genes used for normalization of Northern blots after induction of cell proliferation. Cell Prolif 1993, 26:51|-518.

7. Choi JK, Holtzer S, Chacko SA, Lin ZX, Hoffman RK, Holtzer H: Phorbol esters selectively and reversibly inhibit a subset of myofibrillar genes responsible for the ongoing differentiation program of chick skeletal myotubes. Mol Cell Biol I99I, I I:4473-4482.

8. Wei Q, Guan Y, Cheng L, Radinsky R, Bar-Eli M, Tsan R, Li L, Legerski $R J$ : Expression of five selected human mismatch repair genes simultaneously detected in normal and cancer cell lines by a nonradioactive multiplex reverse transcription-polymerase chain reaction. Pathobiology 1997, 65:293-300.

9. Bjarnason R, Wickelgren R, Hermansson M, Hammarqvist F, Carlsson $B$, Carlsson LM: Growth hormone treatment prevents the decrease in insulin-like growth factor I gene expression in patients undergoing abdominal surgery. J Clin Endocrinol Metab 1998, 83:1566-| 572.

10. Jaschke A, Mi H, Tropschug M: Human T cell cyclophilin I 8 binds to thiol-specific antioxidant protein Aop I and stimulates its activity. J Mol Biol 1998, 277:763-769.

II. Serels S, Day NS, Wen YP, Giraldi A, Lee SW, Melman A, Christ G]: Molecular studies of human connexin 43 (Cx43) expression in isolated corporal tissue strips and cultured corporal smooth muscle cells. Int J Impot Res 1998, I0:135-143.

12. Marten NW, Burke EJ, Hayden JM, Straus DS: Effect of amino acid limitation on the expression of 19 genes in rat hepatoma cells. FASEB / I 994, 8:538-544.

13. Foss DL, Baarsch MJ, Murtaugh MP: Regulation of hypoxanthine phosphoribosyltransferase, glyceraldehyde-3-phosphate dehydrogenase and beta-actin mRNA expression in porcine immune cells and tissues. Anim Biotechnol 1998, 9:67-78.

14. Lemay S, Changchuin M, Singh AK: Cytokine gene expression in the MRL/lpr model of lupus nephritis. Kidney Int 1996, 50:85-93.

15. Wu C, Dias P, Kumar S, Lauder JM, Singh S: Differential expression of serotonin $5-\mathrm{HT} 2$ receptors during rat embryogenesis. Dev Neurosci 1999, 21:22-28.

16. Finnegan MC, Goepel JR, Hancock BW, Goyns MH: Investigation of the expression of housekeeping genes in non-Hodgkin's lymphoma. Leuk Lymphoma 1993, I 0:387-393.

17. Bhatia P, Taylor WR, Greenberg AH, Wright JA: Comparison of glyceraldehyde-3-phosphate dehydrogenase and 28S-ribos- omal RNA gene expression as RNA loading controls for northern blot analysis of cell lines of varying malignant potential. Anal Biochem 1994, 2 I 6:223-226.

18. Goidin D, Mamessier A, Staquet MJ, Schmitt D, Berthier-Vergnes O Ribosomal I8S RNA prevails over glyceraldehyde-3-phosphate dehydrogenase and beta-actin genes as internal standard for quantitative comparison of mRNA levels in invasive and noninvasive human melanoma cell subpopulations. Anal Biochem 200I, 295: |7-2I.

19. Dent AL, Shaffer AL, Yu X, Allman D, Staudt LM: Control of inflammation, cytokine expression, and germinal center formation by BCL-6. Science 1997, 276:589-592.

20. Schmittgen TD, Zakrajsek BA: Effect of experimental treatment on housekeeping gene expression: validation by real-time, quantitative RT-PCR. J Biochem Biophys Methods 2000, 46:69-8I.

21. Huitorel P, Pantaloni D: Bundling of microtubules by glyceraldehyde-3-phosphate dehydrogenase and its modulation by ATP. Eur J Biochem 1985, 150:265-269.

22. Zhang J, Snyder SH: Nitric oxide stimulates auto-ADP-ribosylation of glyceraldehyde-3-phosphate dehydrogenase. Proc Natl Acad Sci U S A 1992, 89:9382-9385.

23. Hobbs MV, Weigle WO, Noonan DJ, Torbett BE, McEvilly RJ, Koch RJ, Cardenas GJ, Ernst DN: Patterns of cytokine gene expression by CD4+ T cells from young and old mice. J Immunol 1993, I 50:3602-36|4

24. Bereta J, Bereta M: Stimulation of glyceraldehyde-3-phosphate dehydrogenase mRNA levels by endogenous nitric oxide in cytokine-activated endothelium. Biochem Biophys Res Commun 1995, 2 1 7:363-369.

25. Chang TJ, Juan CC, Yin PH, Chi CW, Tsay HJ: Up-regulation of beta-actin, cyclophilin and GAPDH in NISI rat hepatoma. Oncol Rep 1998, 5:469-47I.

26. Blanquicett C, Johnson MR, Heslin M, Diasio RB: Housekeeping gene variability in normal and carcinomatous colorectal and liver tissues: applications in pharmacogenomic gene expression studies. Anal Biochem 2002, 303:209-2।4.

27. Lee PD, Sladek R, Greenwood CM, Hudson TJ: Control genes and variability: absence of ubiquitous reference transcripts in diverse mammalian expression studies. Genome Res 2002, I 2:292-297.

28. Lander ES: Array of hope. Nat Genet 1999, 2 1:3-4.

29. Golub TR, Slonim DK, Tamayo P, Huard C, Gaasenbeek M, Mesirov JP, Coller H, Loh ML, Downing JR, Caligiuri MA, Bloomfield CD, Lander ES: Molecular classification of cancer: class discovery and class prediction by gene expression monitoring. Science 1999, 286:53|-537.

30. Wang E, Miller L, Ohnmacht GA, Liu E, Marincola FM: High fidelity mRNA amplification for gene profiling using cDNA microarrays. Nature Biotech 2000, I 7:457-459.

31. Kawakami Y, Eliyahu S, Delgado CH, Robbins PF, Sakaguchi K, Appella E, Yannelli JR, Adema GJ, Miki T, Rosenberg SA: Identification of a human melanoma antigen recognized by tumor-infiltrating lymphocytes associated with in vivo tumor rejection. Proc Nat Acad Sci U S A 1994, 9 I:6458-6462.

32. Yang YH, Dudoit S, Luu P, Lin DM, Peng V, J Ngai, Speed TP: Normalization o fcDNA microarray data: a robust composite method addressing single and multiple slide systematic variation. Nucleic Acids Res 2002, 30:e I5.

33. Hills M: Allocation rules and their error rates. J Roy Stat Soc Ser 1966, B28:|-3|

34. Lachenbruch PA, Mickey MR: Estimation of error rates in discriminant analysis. Technometrics 1968, 10: I-II.

35. Panelli JNMC, Hackett JA, Bettinotti M, Mixon A, Wunderlich J, Parker L, Restifo NP, Ferrone S, Marincola FM: Natural variation of the expression of HLA and endogenous antigen modulates CTL recognition in an in vitro melanoma model. Int J Cancer 1999, 80:78|-790.

36. Riker A, Kammula US, Panelli MC, Wang E, Ohnmacht GA, Steinberg SM, Rosenberg SA, Marincola FM: Threshold levels of gene expression of the melanoma antigen gp 100 correlate with tumor cell recognition by cytotoxic T-lymphocytes. Int J Cancer 2000, 86:818-826.

37. Clark EA, Golub TR, Lander ES, Hynes RO: Genomic analysis of metastasis reveals an essential role for RhoC. Nature 2000 , 406:532-535. 
38. Reimann I, Huth A, Thiele H, Thiele BJ: Suppression of I 5-lipoxygenase synthesis by hnRNP EI is dependent on repetitive nature of LOX mRNA 3'-UTR control element DICE. J Mol Biol 2002, 3 I 5:965-974.

39. Hijazi JNYM, Abati A, Fetsch P, Bettinotti M, Steinberg SM, Rosenberg SA, Marincola FM: Heterogeneous expression of melanomaassociated antigens (MAA) and HLA-A2 in metastatic melanoma in vivo. Int J Cancer 1998, 75:5 17-524.

40. Ohnmacht GA, Wang E, Mocellin S, Abati A, Filie A, Fetsch PA, Riker A, Kammula US, Rosenberg SA, Marincola FM: Short term kinetics of tumor antigen expression in response to vaccination. J Immunol 200I, 167:1809-1820.

41. Solanas M, Moral R, Escrich E: Unsuitability of using ribosomal RNA as loading control for Northern blot analyses related to the imbalance between messenger and ribosomal RNA content in rat mammary tumors. Anal Biochem 200I, 288:99-102.

42. Torma H, Karlsson T, Michaelsson G, Rollman O, Vahlquist A: Decreased mRNA levels of retinoic acid receptor alpha, retinoid $X$ receptor alpha and thyroid hormone receptor alpha in lesional psoriatic skin. Acta Derm Venereol 2000, 80:4-9.

43. Yang IV, Chen E, Hasseman JP, Liang W, Frank BC, Wang S, Sharov V, Saeed Al, White J, Li J, Lee NH, Yeatman TJ, Quackenbush J: Within the fold: assessing differential expression measures and reproducibility in microarray assays. Genome Biol 2002, 3:research0062.

44. Wang E, Marincola FM: Amplification of small quantities of mRNA for transcript analysis. In DNA arrays - A Molecular Cloning Manual Edited by: Bowtell D, Sambrook J. Cold Springs Harbor, NY: Cold Spring Harbor Laboratory Press; 2002:204-213.

45. Kammula US, Lee K-H, Riker A, Wang E, Ohnmacht GA, Rosenberg SA, Marincola FM: Functional analysis of antigen-specific T lymphocytes by serial measurement of gene expression in peripheral blood mononuclear cells and tumor specimens. J Immunol 1999, 163:6867-6879.

46. Marincola FM, Hijazi YM, Fetsch P, Salgaller ML, Rivoltini L, Cormier JN, Simonis TB, Duray PH, Herlyn M, Kawakami Y, Rosenberg SA: Analysis of expression of the melanoma associated antigens MART-I and gp I00 in metastatic melanoma cell lines and in in situ lesions. J Immunother 1996, 19:192-205.

Publish with Bio Med Central and every scientist can read your work free of charge

"BioMed Central will be the most significant development for disseminating the results of biomedical research in our lifetime. "

Sir Paul Nurse, Cancer Research UK

Your research papers will be:

- available free of charge to the entire biomedical community

- peer reviewed and published immediately upon acceptance

- cited in PubMed and archived on PubMed Central

- yours - you keep the copyright

Submit your manuscript here:

http://www.biomedcentral.com/info/publishing_adv.asp
BioMedcentral 